\title{
Design of creativity matrix based on importance - performance model in government executive agencies
}

\author{
Pzhman Pirmon ${ }^{2}$, Naser Hamidi ${ }^{1 \bowtie 凶}$, Nabiollah Mohammadi ${ }^{3}$ and Homa Doroudi ${ }^{4}$ \\ ${ }^{1}$ Ph.D. Student, Department of public Management, Zanjan Branch, Islamic Azad University, Zanjan, Iran \\ $2^{2}$ Associate Prof, Department of Management, Qazvin Islamic Azad University, Qazvin, Iran \\ ${ }^{3}$ Assistant Prof, Department of Management, Zanjan Branch, Islamic Azad University, Zanjan, Iran \\ ${ }^{4}$ Associate Prof, Department of Management, Zanjan Branch, Islamic Azad University, Zanjan, Iran \\ Email:n.hamidi2044@gmail.com
}

\section{ABSTRACT}

The real war of the future countries is not based on energy or markets, but on human capital. Therefore, the need for countries to develop the talents and abilities of knowledge, expertise, skills, and most importantly, the ability of creative thinking. The purpose of this study is to foster creativity by using the Creativity Matrix to fulfill organizational mission. This study designed a matrix consisting of a questionnaire that was identified by barriers and creativity experts and then evaluated their reliability / validity. In the second step, the creativity strategies questionnaire was completed using expert opinion and using the best-worst-caseimportance method. And the position of each in the importance-performance matrix was identified. By analyzing the data, after determining the importance-performance of each strategy in terms of creativity matrix, design in two ways in each organization: a. Designing a separate matrix: An importance-based matrix and a performance-based matrix. B: Matrix Design Integrated, after identifying the importance-function of each strategy, a threedimensional matrix is designed, one in which the importance-performance diagram, one in architecture creativity, and the third in creativity in the process. Organizations vary in terms of applying creativity in architecture and process. Hence, in order to use them optimally, the type of organization and the importance-performance value of each creativity strategy must

Original Article

PII: S232247702000001-10

Rec. 14 January, 2020

Acc. 14 March, 2020

Pub. 25 March, 2020

\section{Keywords}

Creativity,

Creativity Matrix,

Importance-Performance

Model be identified.

\section{INTRODUCTION}

The real war between countries in the next few decades will not be for energy nor markets, but it will be about human capital. This is why countries need more people than before whose talents and abilities are nurtured in a way that enables them to have great knowledge, expertise, skills, and most importantly, the ability to think creatively (Azar et al., 2016). Despite the long history of the existence of creativity in human beings' life, organizations have only recently realized that creativity is the key source of sustainable competitive advantage through the rapid pace of technological changes, global competition and economic uncertainty (Aarabi and Mousavi, 2009). The creativity of the employees helps the survival of the organization because when employees are creative in their job they will be able to offer and apply new and useful ideas about products, performance, services, or procedures of the organization (Sayyedat et al., 2013). Thus, production and benefit from new ideas give the ability to the organization to adapt to the changing conditions, respond to threats and opportunities in a timely manner and develop itself (Seyed Javadin and Jalilian, 2014). One of the factors that lead to the creation of creativity in a community is to make the background and context among people to create a culture in which everyone tries to help grow one another and they help improve the society by their impact on each other. One of the conditions for the creation of new ideas is the peace of mind that is why people need to try to create the conditions in the community where the brain can think and evolve, and lead to new ideas and create the conditions for construction in the community (Samad Aghaei, 2001). Researchers have found that individual creativity reaches a peak when individuals are triggered by internal commitment, challenges, job satisfaction, self-control mechanisms, and self-discipline. They developed their view from individual variables level to the level of contextual variables in their studies. They have found that environments provide opportunities for prosperity of creativity through the elimination of restrictions, and rewards (Mir Miran, 2005). One of the management experts mentions four factors influencing creativity and innovation (King and 
Andersen, 1990) which are as follows: 1. Deployment and recruiting creative and innovative employees in the organization; 2. Appropriate research and financial facilities for innovative efforts; 3. Sufficient freedom to carry out activities and creative efforts; 4. Applying the results of creative activities and giving appropriate responses to creative people; When an organization is designed based on these four factors, creativity and innovation can be developed and improved within the organization (Vakili, 2006). Important factors which are effective on the improvement of creativity and innovation in the organization include social capital, the method of leadership, supportive structure, intellectual capital, management style, organizational trust, organizational communication, organizational support, organizational culture and organizational learning (Alice et al., 2013). Going slow and steady. A creative person is someone who slowly moves along in a specific way like the Pawn in a chess game, without any deviation to left or right. Only in this method the Pawn can become a Queen and have a lot of freedom of action. The Rook strategy is the direct pursuit of the issue and avoiding beating around the bush, creative people, unlike ordinary people, do not hide the issue under unnecessary foliage and useless wastes. To creative people, the issue is important in its pure final form and sub-questions and the minor details are of no importance except for the key to solving the main issue. The Rook strategy means attacking the issue, an unconditional and wholehearted attack. Creative people regularly move out of the ordinary and common route. They approach their intended purpose indirectly in a tortuous way like the Knight in chess. If we consider Rook as a symbol of vertical thinking, the Knight represents the horizontal thinking on the chessboard, and both of them worth nothing without each other. A creative person attacks a point like a Rook with high intensity and focus, but they choose a different angle than the direct route for this goal. The Bishop strategy is a way for continuing the ideas and achievements that we have obtained by playful ramblings of the Knight strategy. While playing chess, a creative person leaves his king behind in the chessboard and tries to win the game by using his other chess pieces. And at the same time, they do not neglect the dangers that threaten the King piece. Creativity is the same as mastering normative and transient ways and realizing that only relying on the movement of the King will have no outcome other than loss. The Queen strategy is the key to creativity. The Queen strategy is related to the simultaneous use of the skills of Rook, to keep track of the issue vertically, and also about using the skills of Bishop (horizontal) to attack (side-by-side). The possibility of a stubborn Pawn becoming a Queen can be considered as the importance of perseverance and the pursuit of small ideas (Bassett-Jones, 2005).

The creativity matrix: creativity in architecture and process in management

Based on the matrix of creativity the project or organization environment is divided into two parts which include creativity in architecture and creativity in the process. Architectural creativity is related to the type of creativity needed in project structure (or in production) or the organization and it is connected to their results. Creativity in the process is also related to management methodology and management practices.

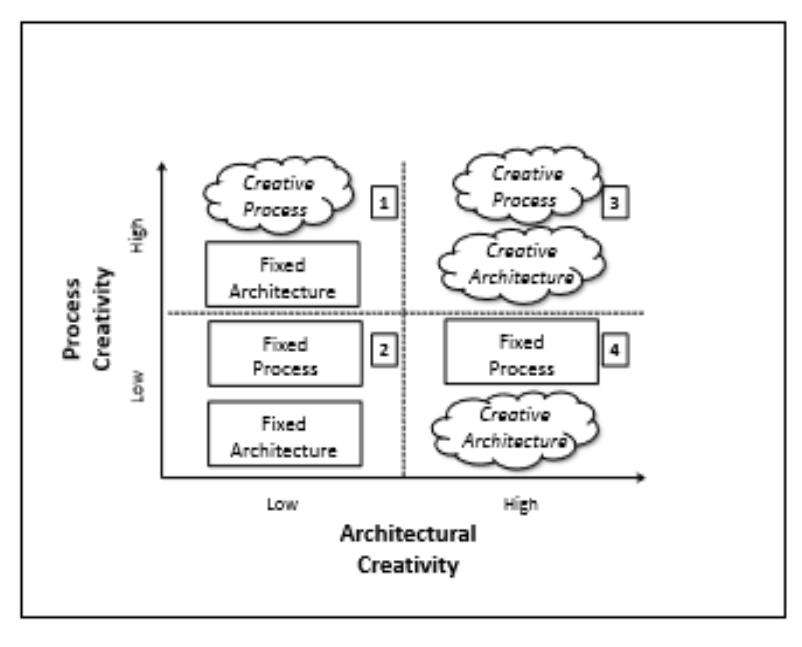

Exhibit 1: The Project Creativity Matrix.

This matrix has four quadrants in two dimensions and there is a distinction between creativity in architecture and creativity in the process. Any manager of an organization must be aware of this distinction, because different management strategies, tools, and techniques are needed for every quarter of the matrix. This matrix offers specific recommendations on the use and application of creativity in both the process and architecture of the organizational departments. Simple "high" and "low" measurements are used for each type of creativity in the creativity matrix and as a result the matrix has four sections. Vertical coordinates show the information on process creativity while horizontal coordinates represent architectural creativity. An appropriate creative strategy depends on the organization, industry, company and maybe even the individual project (SueChan and Hempel, 2016). The first quarter: high process creativity, low architectural creativity. This quarter indicates the projects or organizations that are known to have low architectural creativity but 
high process creativity. Projects related to the production of artwork, traditional publishing, advertising, and public relations, are in this category. The second quarter: low process creativity, low architectural creativity. This quarter indicates projects or organizations that are specified by low creativity in architecture and process. Service activities such as system upgrades, software maintenance, and information technology projects as well as maintenance projects are placed in this category. The third quarter: high process creativity, high architectural creativity .This quarter shows organizations (or more precisely, different types of projects) and it is characterized by high creativity in architecture and process. This category includes the development of information technology systems as well as the development and research of medicines. The fourth quarter: low process creativity, high architectural creativity. This quarter shows projects with very creative architecture but a constant trend and low creativity of the process. Accounting and defense systems are placed into this category.

\section{The analysis of importance and performance}

The analysis of importance and performance is taken from one of the methods of gap analysis. This technique was first presented by John Martilla and John James in 1977. This technique is very similar to the SERVQUAL technique in terms of data collection. The analysis of importance and performance is an effective tool for evaluating an organization's competitive position, identification of opportunities for improvement, designing marketing strategies and providing purposeful services. Martilla and James (1977) for the first time presented the importanceperformance analysis for identifying and prioritizing product features or the service which the organization can focus on maximizing customer satisfaction. Effective suggestions can be made for managers through creating a two-dimensional matrix which its vertical axis shows the perception of the customer about the performance (quality) of each feature and its horizontal axis shows the importance of that feature in customer's decision making. This two-dimensional matrix is called the importanceperformance matrix. Since the separate analysis of data on performance dimension and importance dimension might not be significance especially when each dataset is studied simultaneously, therefore, data on the importance level and performance of the indicators is shown on a two-dimensional network in which the vertical axis represents the dimension of importance and the horizontal axis represents the dimension of performance. This two-dimensional grid is called the importance / performance matrix. In fact, the role of the importance / performance matrix consists of four parts or quadrants. Each quarter has a specific strategy, which helps the decision-making process. This matrix is used for the identification of the priority of indicators for improvement.

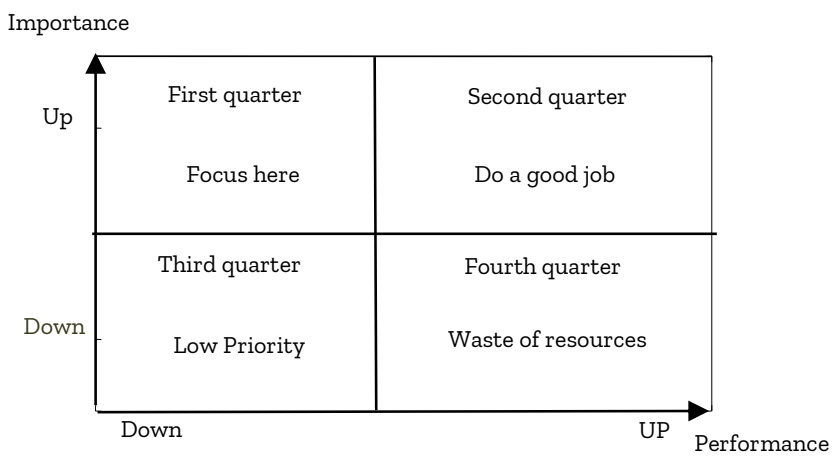

Figure 2. Quadrant model of performance-importance analysis

Four quadrants can be distinguished regarding how important each indicator is (optimal status) and how well is the organization performing in terms of this indicator (current status): The indifference scope: Low performance - low importance .The dissipation scope: High performance

- Low importance. The weaknesses scope: Low performance - high importance The acceptable scope: High performance - high importance. The main gap in the importance-performance analysis model exists in the second and fourth quarters. If most of the indicators are placed in the second quarter it means the organization has invested in indicators that are not worth much and the performance is high in terms of unimportant indicators. If most of the indicators are in the fourth quarter, it means that the organization has a weak performance in terms of important indicators. The strategy of the organization must attempt to initially move the elements from the fourth quarter to the first quarter and delete all the elements of the second and third quarters. The importance-performance analysis is very convenient for SERVQUAL analysis and competitive analysis. Usually, a questionnaire with a range of 5,7 or 9 degrees is used for data collection (Timothy, 2015). Creativity researchers developed their view from individual variables level to the level of contextual variables in their studies. They have found that environments provide opportunities for prosperity of creativity through the elimination of restrictions, and rewards (Tai and Mai, 2016). In the rest of the review of the literature, we will review the most recent related studies and their results. 


\section{METHODOLOGY}

The present study is applied research in terms of the nature of the problem and the purpose of the study. And in terms of the type of implementation, it is a descriptive survey study. The research steps are as follows: Step one: data collection .To design the matrix, at first, data was collected about creativity, creativity barriers, creativity propellants, creativity strategies, importance-performance model, and creativity matrix were collected using the library method and studying the books, authentic articles and magazines. Step two: Designing a basic questionnaire about the propellants, and creativity barriers, and gathering Expert Opinion. After collecting data based on previous models of factors affecting employee creativity and also the creativity barriers are summarized and the initial questionnaires were designed. Step three: Expert opinion analysis and data validation. After designing the questionnaire of the creativity propellants, and create barriers, the objectives of the test were explained to the experts and the operational definitions of the content of the questions were outlined. The content validity ratio (CVR) method was used to assess content validity. In this method, 15 experts were asked to classify each question according to the Likers scale "there is a high fit", "there is a fit", "and there is a low fit", "and there is no fit". And then according to the following formula, the Law she Content validity ratio was calculated.

$$
C V R=\frac{n_{E}-\frac{N}{r}}{\frac{N}{r}}
$$

In this formula we have: $\mathrm{N}$ : Total number of the experts/NE: The number of experts who chose the "necessary" option. Thus, by considering the number of experts, the questions whose validity was above 0.49 were confirmed and the validity of the remaining questions was rejected.

After calculating the content validity by the propellants, the validity was confirmed for creating a background for individual creativity, individual factors (internal commitment, challenge, job satisfaction, and self-control and self-discipline mechanisms), organizational Culture, KnowledgeBased Strategies and Policies, senior management support, the style of leadership, organizational structure, organizational atmosphere and strengthening the values of the organization. Also in terms of barriers, the content validity was confirmed for lack of confidence, fear of criticism and failure, lack of mental focus, individual factors (lack of motivation for creativity, etc.), environmental factors (a creative person not being accepted acceptance by colleagues and managers, etc.), lack of intrinsic motivation, pressure to do work and the lack of a suitable environment to create and nurture creativity.

Step 4: Development of a questionnaire of creativity strategies and obtaining the opinions of the expert's .In this section of the study, the strategies identified in this study were evaluated using the bestworst method. At first, the questionnaires of the research were designed to evaluate research strategies using the best-worst method and then they were given to the experts. After the questionnaires were completed by the experts we evaluated and prioritized research strategies by using the relations in the best-worst method.

The next step in the best-worst method is the selection of the best (most important) and worst (least important) strategy. After identifying the best and least important strategy, the experts provide their opinion based on the paired comparisons questionnaire, regarding the superiority of the best strategy over other strategies and the superiority of all strategies over the least important strategy.

Table 1. The List of Strategies

\begin{tabular}{lc}
\hline No. & Strategies \\
\hline 1 & Pawn \\
2 & Rook \\
3 & Knight \\
4 & Bishop \\
5 & Queen \\
6 & King \\
\hline
\end{tabular}

Table 2. The mean of expert opinions on the superiority of the best strategy over other strategies

\begin{tabular}{lllllll} 
Strategies & Pawn & Rook & Knight & Bishop & Queen & King \\
\hline $\begin{array}{l}\text { Best } \\
\text { Strategy }\end{array}$ & 4.816 & 1 & 3.519 & 3.287 & 2.724 & 2.701 \\
\hline
\end{tabular}

Table 3. The mean of expert opinions on the superiority of all the strategies compared to the worst strategy

\begin{tabular}{lc}
\hline Strategies & Worst Strategy \\
\hline Pawn & 1 \\
Rook & 4.816 \\
Knight & 3.437 \\
Bishop & 3.650 \\
Queen & 3.727 \\
King & 3.103 \\
\hline
\end{tabular}

The next step is to find the weight of each strategy. To that end, based on the relations in the best-worst method, initially, the mathematical model of the problem was formed as follows.

$\min \xi$

$\left|\frac{W 2}{W 1}-4.816\right| \leq \xi$ 

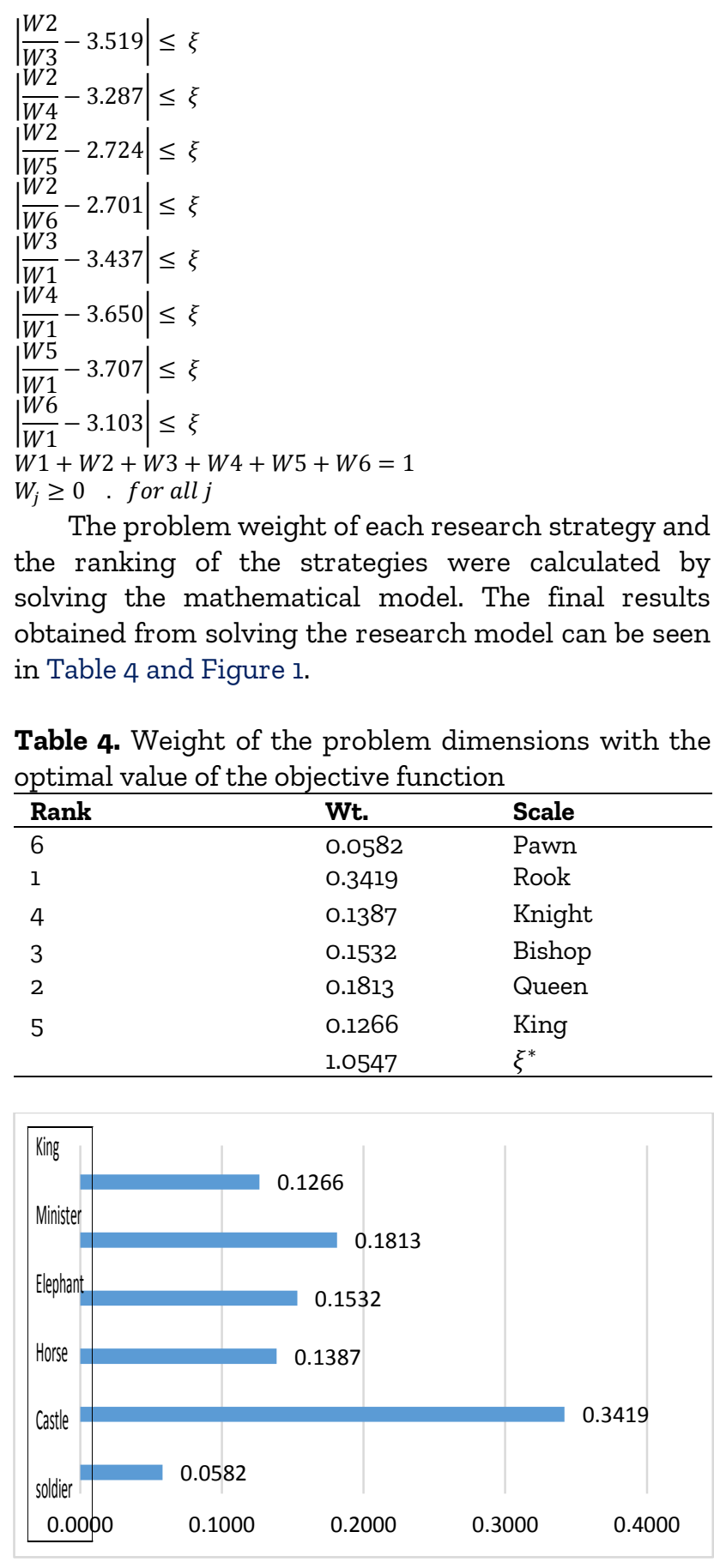

Figure 4. The amount of the importance of each strategy

\section{RESULTS}

As it is clear from the results of the tables above, the Rook strategy has achieved the first rank among all strategies in the study because it has gained the most weight among research strategies. The Queen and Bishop strategies have the second and third place after the Rook strategy. The weight of the importance of the other strategies and the rankings obtained for them can be seen in the table above separately. After the recognition of the importance and performance of each of the strategies, the creativity matrix can be designed according to the type of organization. This design can be done in the two following methods: A. Designing creativity matrix separately: In this mode, after identifying the importance and performance of each strategy in the organization, one creativity matrix is designed based on the importance and one creativity matrix is designed based on performance.

So, in the importance-based creativity matrix, the position of each strategy in the matrix can be seen in two dimensions: creativity in architecture and creativity in the process: Designing the Matrix of creativity in a combined way: In this mode, after identifying the importance and performance of each strategy in the organization, a three-dimensional creativity matrix is designed. One dimension of this matrix shows the importance-performance diagram, another dimension shows creativity in architecture and the last dimension shows creativity in the process.

\section{IISCUSSION AND CONCLUSION}

The researches mentioned in the literature review are some of the most important researches on creativity and the use of creativity in organizations, and as it could be seen, those studies only addressed a part of creativity. But the present study has addressed this issue more comprehensively with various dimensions. Finally, we can conclude that organizations differ in terms of using creativity in architecture and process.

Therefore, the type of organization and the importance and performance of each creative strategy must be identified to use the employee creativity optimally and design a creativity matrix so that the goals and objectives of the organization can be achieved. It is suggested based on the findings of the study that the managers of the organization identify the barriers and propellants of creativity for efficient and effective use of creativity. They should also eliminate removable barriers and make the most use of the best propellants, and finally, consider creativity strategies in architecture and management processes.

Due to the difficulty of designing the creativity matrix in the three-dimensional combined form (one dimension of importance-performance analysis, one dimension of creativity in architecture and the third dimension of creativity in process), as well as understanding its dimensions and interpreting it, caution must be observed and the people who are skilled in the field must be used to design it. 
Pirmon et al., 2019

Table 5. The advantages of the present research compared to previous research

The amount of attention and focus on different dimensions of creativity

\begin{tabular}{|c|c|c|c|c|c|c|}
\hline 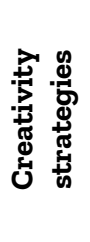 & 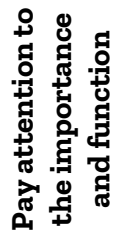 & 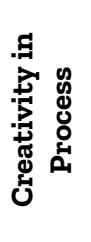 & 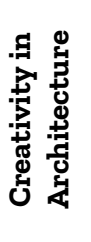 & 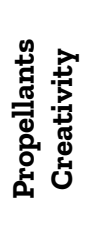 & 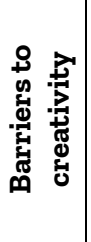 & Research title \\
\hline$\sqrt{ }$ & $\sqrt{ }$ & $\sqrt{ }$ & $\sqrt{ }$ & $\sqrt{ }$ & $\sqrt{ }$ & Existence Research \\
\hline- & - & $\sqrt{ }$ & - & $\sqrt{ }$ & - & Visionary leadership and employee creativity in China (Zhou et al., 2018) \\
\hline- & - & $\sqrt{ }$ & - & $\sqrt{ }$ & - & $\begin{array}{l}\text { The impact of leaders' technical competence on employees' innovation } \\
\text { and learning (Van Minh et al., 2017) }\end{array}$ \\
\hline- & - & $\sqrt{ }$ & - & $\sqrt{ }$ & $\sqrt{ }$ & $\begin{array}{l}\text { Proactive personality, organizational context, employee creativity and } \\
\text { innovative capability Evidence from MNCs and domestic corporations } \\
\text { (Tai and Mai, 2016) }\end{array}$ \\
\hline- & - & $\sqrt{ }$ & - & $\sqrt{ }$ & - & $\begin{array}{l}\text { Transformational leadership, innovation climate, creative self-efficacy } \\
\text { and employee creativity: A multilevel study (Jaiswal and Dhar, 2015) }\end{array}$ \\
\hline- & - & $\sqrt{ }$ & - & $\sqrt{ }$ & - & $\begin{array}{l}\text { Network structure, organizational learning culture, and employee } \\
\text { creativity in system integration companies: The mediating effects of } \\
\text { exploitation and exploration (Hahn et al., 2015) }\end{array}$ \\
\hline- & - & $\sqrt{ }$ & - & $\sqrt{ }$ & $\sqrt{ }$ & $\begin{array}{l}\text { Studying the links between organizational culture, innovation, and } \\
\text { performance in Spanish companies (Naranjo-Valencia et al., 2016) }\end{array}$ \\
\hline- & - & $\checkmark$ & - & $\sqrt{ }$ & $\sqrt{ }$ & $\begin{array}{l}\text { The creativity-performance relationship: how rewarding creativity } \\
\text { moderates the expression of creativity (Sue-Chan and Hempel, 2016) }\end{array}$ \\
\hline- & - & $\sqrt{ }$ & - & $\sqrt{ }$ & - & $\begin{array}{l}\text { Overcoming work-related stress and promoting employee creativity in } \\
\text { hotel industry: the role of task feedback from supervisor: Overcoming } \\
\text { work related stress and promoting employee creativity in hotel industry } \\
\text { (Hon et al., 2013) }\end{array}$ \\
\hline- & - & $\sqrt{ }$ & - & $\sqrt{ }$ & $\sqrt{ }$ & $\begin{array}{l}\text { Impact factors; SSCI journals; Academic success; Creativity; Academic } \\
\text { freedom; Performance indicators }\end{array}$ \\
\hline- & - & - & - & $\sqrt{ }$ & - & $\begin{array}{l}\text { Work environment and atmosphere: The role of organizational support } \\
\text { in the creativity performance of tourism and hospitality organizations }\end{array}$ \\
\hline- & - & - & - & $\sqrt{ }$ & - & $\begin{array}{l}\text { Creativity cognitive style, conflict, and career success for creative } \\
\text { entrepreneurs (Chen et al., 2015) }\end{array}$ \\
\hline- & - & $\sqrt{ }$ & - & $\sqrt{ }$ & $\sqrt{ }$ & Managing creativity in business market relationships \\
\hline
\end{tabular}

\section{REFERENCES}

Hon, A. H., Chan, W. W., \& Lu, L. (2013). Overcoming work-related stress and promoting employee creativity in hotel industry: The role of task feedback from supervisor. International Journal of Hospitality Management, 33, 416-424. https://doi.org/10.1016/j.ijhm.2012.11.001, Google Scholar

Aarabi, S. M., \& Mousavi, S. (2009). Strategic knowledge management model for research centers performance promotion. Quarterly Journal of Research and Planning in Higher Education, 15(1), 1-26. URL: http://journal.irphe.ac.ir/article-1-391-en.html, Google Scholar

Azar, A., Khosravani, F., \& Jalali, R (2016). Research on the Soft Operations Problem Structuring Approaches. Industrial Management Institute.

Bassett-Jones, N. (2005). The paradox of diversity management, creativity and innovation. Creativity and Innovation Management, 14(2), 169-175. https://doi.org/10.1111/j.14678691.00337.x, Google Scholar
Sue-Chan, C., \& Hempel, P. S. (2016). The creativity-performance relationship: How rewarding creativity moderates the expression of creativity. Human Resource Management, 55(4), 637-653. https://doi.org/10.1002/hrm.21682, Google Scholar

Timothy, D. J. (2015). Impact factors: Influencing careers, creativity and academic freedom. Tourism Management, 51, 313-315. https://doi.org/10.1016/j.tourman.2015.05.009, Google Scholar

Tai, H. T., \& Mai, N. Q. (2016). Proactive personality, organizational context, employee creativity and innovative capability. International Journal of Organizational Analysis. https://doi.org/10.1108/IJOA-04-2015-0857, Google Scholar

Naranjo-Valencia, J. C., Jiménez-Jiménez, D., \& Sanz-Valle, R. (2016). Studying the links between organizational culture, innovation, and performance in Spanish companies. Revista Latinoamericana de Psicología, 48(1), 30-41. https://doi.org/10.1016/j.rlp.2015.09.009, Google Scholar

King, N., \& Andersen, N. (1990). Innovation and creativity in working groups. MA West and Farr, Innovation and creativity at work. Google Scholar 
Zhou, L., Zhao, S., Tian, F., Zhang, X., \& Chen, S. (2018). Visionary leadership and employee creativity in China. International Journal of Manpower. https://doi.org/10.1108/IJM-04-20160092, Google Scholar

Martilla, J. A., \& James, J. C. (1977). Importance-performance analysis. Journal of Marketing, 41(1), 77-79. https://doi.org/10.1177/002224297704100112, Google Scholar

Hahn, M. H., Lee, K. C., \& Lee, D. S. (2015). Network structure, organizational learning culture, and employee creativity in system integration companies: The mediating effects of exploitation and exploration. Computers in Human Behavior, 42, 167-175. https://doi.org/10.1016/j.chb.2013.10.026, Google Scholar

Chen, M. H., Chang, Y. Y., \& Lo, Y. H. (2015). Creativity cognitive style, conflict, and career success for creative entrepreneurs. Journal of Business Research, 68(4), 906-910. https://doi.org/10.1016/j.jbusres.2014.11.050, Google Scholar

Mir Miran, S. J. (2005). Creativity and Innovation (Individual, Group, Organizational), Gohar Publications, First Edition.

Jaiswal, N. K., \& Dhar, R. L. (2015). Transformational leadership, innovation climate, creative self-efficacy and employee creativity: A multilevel study. International Journal of
Hospitality Management, 51, 30-41. Google Scholar, https://doi.org/10.1016/j.ijhm.2015.07.002

Van Minh, N., Badir, Y. F., Quang, N. N., \& Afsar, B. (2017). The impact of leaders' technical competence on employees' innovation and learning. Journal of Engineering and Technology Management, 44, 44-57. Google Scholar, https://doi.org/10.1016/j.jengtecman.2017.03.003

Samad Aghaei, J. (2001). Individual and Group Creativity Techniques, Public Management Training Center Publications, First Edition.

Sayyedat, S. A., Chupani, H., Kazempour, M., Malki Hassanvand, M. (2013). Identifying factors influencing the organizational innovation and presetting solutions for its development. Initiative and Creativity in Human Science, 3 (1), 71-110.

Seyed Javadin, S. R. \& Jalilian, H. (2014). Management Theories, Knowledge view, Third Edition.

Shalley, C. E., \& Gilson, L. L. (2004). What leaders need to know: A review of social and contextual factors that can foster or hinder creativity. The leadership quarterly, 15(1), 33-53. Google $\underline{\text { Scholar }}$

Vakili, Sh (2006). Creativity, Andishe Sara Publications and Kanoone Khorshid. 